\title{
Transcriptional dynamics of the sex chromosomes and the search for offspring sex-specific antigens in sperm
}

\author{
Peter J I Ellis, Yong Yu ${ }^{1}$ and Shujun Zhang ${ }^{1}$ \\ Mammalian Molecular Genetics Group, Department of Pathology, University of Cambridge, Tennis Court Road, \\ Cambridge, CB2 1QP, UK and ${ }^{1}$ Key Laboratory of Agricultural Animal Genetics, Breeding and Reproduction, \\ Huazhong Agricultural University, Wuhan, Hubei 430070, People's Republic of China
}

Correspondence should be addressed to P J I Ellis; Email: pjie2@cam.ac.uk

P J I Ellis and Y Yu contributed equally to this work

\begin{abstract}
The ability to pre-select offspring sex via separation of $X$ - and Y-bearing sperm would have profound ramifications for the animal husbandry industry. No fully satisfactory method is as yet available for any species, although flow sorting is commercially viable for cattle. The discovery of antigens that distinguish X- and Y-bearing sperm, i.e. offspring sex-specific antigens (OSSAs), would allow for batched immunological separation of sperm and thus enable a safer, more widely applicable and high-throughput means of sperm sorting. This review addresses the basic processes of spermatogenesis that have complicated the search for OSSAs, in particular the syncytial development of male germ cells, and the transcriptional dynamics of the sex chromosomes during and after meiosis. We survey the various approaches taken to discover OSSA and propose that a whole-genome transcriptional approach to the problem is the most promising avenue for future research in the field.

Reproduction (2011) 142 609-619
\end{abstract}

\section{Introduction}

In mammalian spermatogenesis, Mendelian segregation of sex chromosomes during meiosis leads to the production of a 50:50 ratio of X-bearing sperm (leading to female offspring) and Y-bearing sperm (giving rise to male offspring). The ability to sort $X$ from $Y$ sperm and thus to pre-select the sex of offspring has profound implications for the efficiency and sustainability of livestock production, for example preferential production of female calves in the dairy industry or male calves in the beef industry. There is also an approved role for sex selection in human medicine to avoid the transmission of sex-linked diseases.

Sperm sorting requires the existence of detectable differences between $X$ and $Y$ sperm: to date, the only widely accepted example of such a difference is that Y sperm have lower DNA content due to the smaller size of its chromosome. Various physical parameters based on this difference have been proposed as a basis for sperm sorting, for example Percoll gradient centrifugation based on hypothetical differential density of $X$ and $Y$ sperm (Kaneko et al. 1983) or albumin gradient separation based on hypothetical differential motility of the 'lighter' Y sperm (Beernink et al. 1993). Disappointingly, in most cases, follow-up studies failed to confirm the results of these studies. For example, albumin separation does not enrich for Y-bearing sperm (Chen et al. 1997), there are no differences in dimensions or dimensional distributions between human $X$ and $Y$ sperm or spermatids (Hossain et al. 2001), and bull $Y$ sperm do not swim faster than $X$ sperm (Penfold et al. 1998). Thus, the only unequivocally proven method for sperm sorting is direct detection of DNA content by staining with a DNA-binding dye such as Hoechst 33342 followed by flow cytometric separation of $X$ and $Y$ sperm. This technique has become commercially viable in cattle despite requiring expensive equipment for the complex separation procedure; however, the number of sexed sperm produced per unit time is limited (Seidel 2003). Moreover, results are highly variable between individual bulls, likely due to the damage caused by staining and/or subsequent u.v. scanning (Rath et al. 2009).

There is, therefore, considerable interest in developing simpler and more efficient methods to separate $X$ from $Y$ sperm. Identification of a specific cell surface marker for immunoselection would represent a major advance in this field by a) allowing for batch selection and b) reducing the safety issues associated with DNA damage from the intercalating dye/u.v. detection methods currently used. It should be noted that while previous studies (e.g. Howes et al. 1997, Sang et al. 2011) have used the term 'sex-specific antigen' (SSA) or 'sex-specific 
protein' to refer to such markers, this terminology has the potential for ambiguity. The term 'SSA' has historically been used to refer to transplantation antigens differing between male and female individuals. While it was initially surmised that such SSAs would prove useful in distinguishing $\mathrm{X}$ - and Y-bearing sperm, this has not turned out to be the case due to transcript sharing (see Syncytial development of male germ cells). We, therefore, propose the term offspring SSA (OSSA), specifically referring to markers that distinguish the two categories of sperm and are therefore indicative of offspring sex.
The term 'sex chromosome-specific protein' (SCSP; Blecher et al. 1999), while useful, is not appropriate as OSSAs need not necessarily be encoded by the sex chromosomes (see Box 1).

This review discusses the processes through which OSSAs arise, including transcription, compartmentalisation and translation of sex-linked genes in spermatids, and surveys past and future research avenues in the ongoing search for OSSAs. Several previous reviews (e.g. Gledhill 1988, Bradley 1989, Hendriksen 1999) are available that provide valuable historical context.

\section{Box 1 Models of OSSA formation}

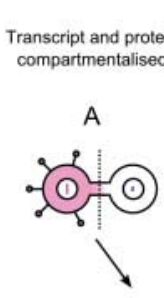

Transcript

translation after bridges break

B

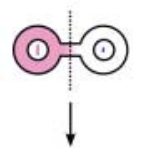

100
Transcription and translation after
bridges break

C
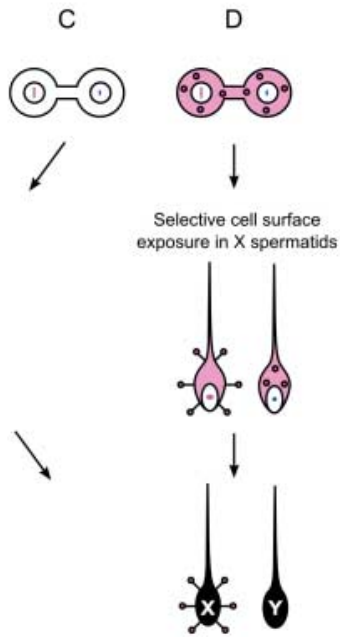

Transcript and protein present in all spermatids

E

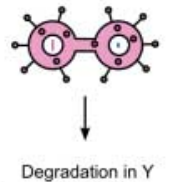

Degradation in
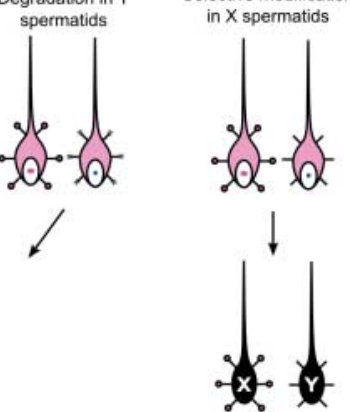

There are several potential routes by which individual spermatozoa may become distinguishable from each other. For clarity, we here illustrate the development of $X$ and $Y$ sperm from a pair of linked spermatids, with the $X$ sperm bearing an offspring sex-specific antigen (OSSA) on the surface. In models A through $\mathrm{C}$, the OSSA arises via compartmentalisation of a sex-linked transcript and/or its encoded protein product. In model A, transcription and translation occur in early stage spermatids, hence both transcript and protein must remain compartmentalised, for example by binding to the cytoskeleton (mRNA) or immediate insertion into the cell membrane (protein). Alternatively, in model B, the transcript is expressed in early spermatids and compartmentalised; however, translation is delayed until later stages of development, after the breakage of the cytoplasmic bridges. Transcriptional delay is a hallmark of many spermatid-expressed genes (reviewed in Kleene (2003)). Finally, in model C, both transcription and translation occur after bridge breakage. This model is the least likely, given the condensed nature of the sperm genome at this point and the greatly reduced potential for transcription (see Transcriptional and translational activity in spermatozoa).

In models D through $\mathrm{F}$, a non-compartmentalised gene nevertheless generates an OSSA via differential protein localisation (D), degradation (E), or post-translational modification (F) in X- and Y-bearing cells. These routes could potentially lead to autosomally encoded OSSAs as well as sex-linked OSSAs. However, these latter three models present a bootstrapping problem: if there is a difference in (e.g.) translational activity between $X$ and $Y$ spermatids, how does this difference itself arise? Ultimately, any antigenic difference must be rooted in a difference at the nucleic acid level. We therefore conclude that if OSSAs exist, there will be a detectable transcriptional difference between X-and Y-bearing spermatids or sperm due to compartmentalisation of one or more sex-linked genes. However, the downstream consequences of this (e.g. from compartmentalisation of a sexlinked transcription factor) need not be restricted to the sex chromosomes and thus this should be taken into account in any candidate gene approach to OSSA discovery. 


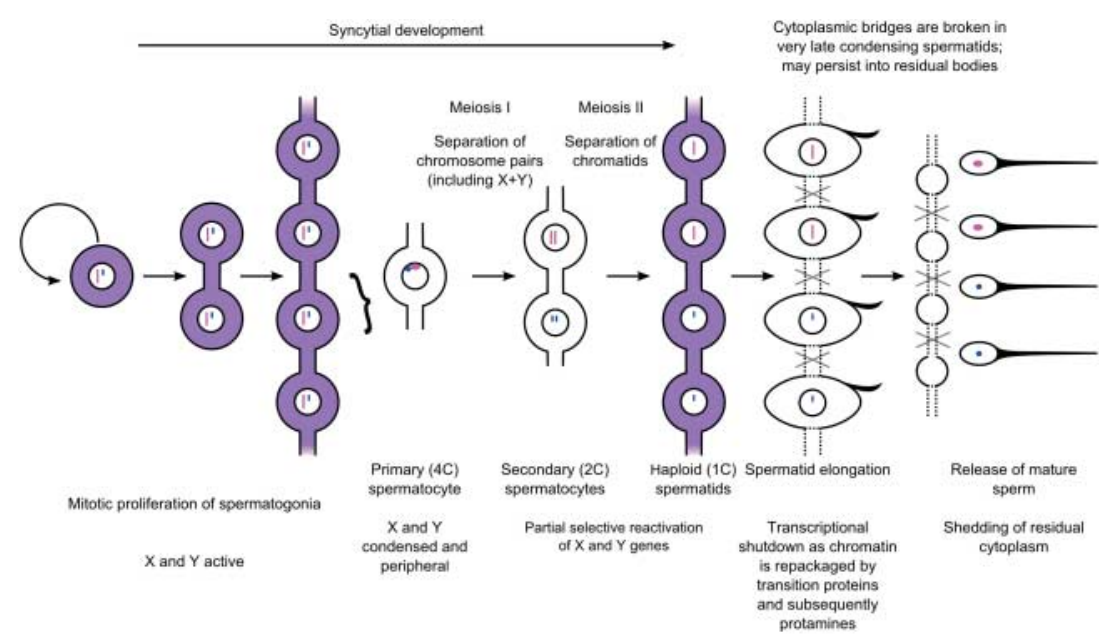

Figure 1 Schematic showing the syncytial development of sperm and the transcriptional status of the $X$ (pink) and $Y$ (blue) chromosomes at each stage. Sharing of transcripts across the bridges leads to the presence of both $X$ - and Y-derived mRNAs in germ cells (purple).

\section{Syncytial development of male germ cells}

Spermatogenesis is a complex physiological process occurring in the seminiferous tubules of the testis (Fig. 1), in which germ cells proliferate and differentiate to form the mature haploid spermatozoa. This process can be divided into three phases: a) mitotic proliferation of spermatogonial stem cells to generate progressively more differentiated progeny, b) meiotic divisions generating haploid spermatids, and c) spermiogenesis, during which the spermatids elongate, shed most of their cytoplasm, undergo nuclear condensation and develop sperm-specific organelles such as the acrosome and flagellum.

During spermatogenesis, cytokinesis is incomplete during mitotic and meiotic divisions. Germ cells that arise from the same undifferentiated $A_{1}$ spermatogonium remain connected to each other by intercellular bridges $(0.1-2 \mu \mathrm{m})$, which persist until late spermiogenesis (Dym \& Fawcett 1971, Guo \& Zheng 2004). The precise point at which these bridges are broken is unclear. Some studies indicate that they persist until the residual bodies are shed, while others indicate that they are broken before this point and connection between residual bodies is rare (Breucker et al. 1985). This may reflect species differences in post-meiotic development.

Several studies have provided strong evidence that spermatids share transcripts and/or gene products across the cytoplasmic bridges during spermiogenesis. Transgenic mice hemizygous for a spermatid-specific chimeric gene consisting of the mouse protamine 1 ( $m P 1$ ) transcriptional regulatory sequence fused with the human $\mathrm{GH}(h G H)$ structural gene carry the $\mathrm{hGH}$ protein in nearly all $(\sim 90 \%)$ epididymal spermatozoa, despite the fact that the transgene is only present in $50 \%$ of spermatids. This indicates that the transcript, the gene product or both is shared (Braun et al. 1989). Analysis of mice carrying Robertsonian translocations of chromosome 16 shows that sharing occurs at the transcript level for protamine (Caldwell \& Handel
1991). Further indirect evidence is provided by the existence of essential spermatid-specific genes on the sex chromosomes (see Sex chromosome transcriptional activity in spermatids), which must be shared in order to allow spermatogenesis to continue. This syncytial development is a significant hurdle to immunological sperm separation: if all transcripts and/or gene products are shared evenly, then there can be no antigenic means to distinguish $X$ from $Y$ sperm. Box 1 presents a number of models showing how sperm become non-equivalent despite the presence of cytoplasmic bridges: this may potentially lead to sex-encoded OSSAs given a nonshared, sex-linked transcript that encodes a cell surface protein or even to autosomally encoded OSSAs given a non-shared, sex-linked transcript that encodes an enzyme involved in post-translational modification of autosomally encoded cell surface proteins.

\section{Sex chromosome transcriptional activity in spermatids}

The sex chromosomes undergo widespread radical changes in transcriptional status during spermatogenesis owing to the fact that their axes remain largely unsynapsed during meiosis. During meiosis, they become transcriptionally silenced and migrate to a peripheral location within the nucleus, remaining silent throughout diplotene (Kierszenbaum \& Tres 1974; reviewed by McKee \& Handel (1993)). This phenomenon, originally known as meiotic sex chromosome inactivation, is now known to be part of a more general meiotic silencing of unsynapsed chromatin (MSUC), which has been suggested to be a defence against selfish elements such as retroposons (Turner et al. 2005). No protein-coding genes are known to escape MSUC, although $\mathrm{X}$-linked genes that are transcribed into miRNAs appear not to be silenced (Song et al. 2009).

After meiosis, sex chromosomal transcriptional repression is partially maintained, and the sex chromosomes 
Table 1 Sex-linked genes expressed in spermatids. References are given for the first published reports of expression in spermatids and (where different) for the first report of $X / Y$ linkage.

\begin{tabular}{|c|c|c|c|c|}
\hline Gene & Species & Map & Copies & References \\
\hline 1700003E24Rik & M & $\mathrm{X}$ & 3 & Ellis et al. (2005) and Mueller et al. (2008) \\
\hline 1700010D01Rik & M & $x$ & 2 & Ellis et al. (2005) and Mueller et al. (2008) \\
\hline 1700020N15Rik & M & $\mathrm{X}$ & 2 & Mueller et al. (2008) \\
\hline 1700042B14Rik & M & $\mathrm{X}$ & 4 & Mueller et al. (2008) \\
\hline 4921511M17Rik & M & $X$ & 4 & Mueller et al. (2008) \\
\hline 4930453H23Rik & M & $\mathrm{X}$ & 3 & Ellis et al. (2005) \\
\hline 4930524N10Rik & M & $\mathrm{X}$ & 5 & Mueller et al. (2008) \\
\hline 4930567H17Rik & M & $\mathrm{X}$ & 2 & Mueller et al. (2008) \\
\hline 4933434C23Rik & M & $\mathrm{X}$ & 3 & Mueller et al. (2008) \\
\hline AK006152 & M & $\mathrm{Y}$ & $2+$ & Ellis et al. (2005) and Ferguson et al. (2009) \\
\hline AKAP4 & $\mathrm{H}, \mathrm{M}$ & $\mathrm{X}$ & 1 & Carrera et al. (1994) and Moss et al. (1997) \\
\hline Asty & M & $\mathrm{Y}$ & Many & Touré et al. (2005) \\
\hline Bex1 & M & $\mathrm{X}$ & 1 & Brown \& Kay (1999) and Yang et al. (2002) \\
\hline$C d y$ & $\mathrm{C}, \mathrm{H}$ & $\mathrm{Y}$ & & Lahn \& Page (1999), Kleiman et al. (2003), and Wang et al. (2008) \\
\hline Cypt genes & M & Mostly X & 15 & Ellis et al. (2005) and Hansen et al. (2006) \\
\hline Daz & $\mathrm{H}$ & $\mathrm{Y}$ & 4 & Reijo et al. (1995) and Habermann et al. (1998) \\
\hline E330016L19Rik & M & $\mathrm{X}$ & $21+$ & Mueller et al. (2008) \\
\hline EG245347 & M & $\mathrm{X}$ & 1 & Ellis et al. (2005) \\
\hline EG434797 & M & $\mathrm{X}$ & 2 & Mueller et al. (2008) \\
\hline EG546347 & M & $\mathrm{X}$ & 1 & Ellis et al. (2005) \\
\hline Esx1 & M & $\mathrm{X}$ & 1 & Branford et al. (1997) and Li et al. (1997) \\
\hline Gmcl11 & M & $x$ & $21+$ & Ellis et al. (2005) \\
\hline H2al1 & M & $\mathrm{X}$ & $14+$ & Ellis et al. (2005), Govin et al. (2007), and Ferguson et al. (2009) \\
\hline $\mathrm{H} 2 \mathrm{al} 2 \mathrm{y}$ & M & $\mathrm{Y}$ & 2 & Ellis et al. (2005) and Ferguson et al. (2009) \\
\hline LOC245376 & M & $X$ & 3 & Mueller et al. (2008) \\
\hline LOC278181 & M & $\mathrm{X}$ & 3 & Mueller et al. (2008) \\
\hline LOC207318 & M & $\mathrm{X}$ & $2+$ & Mueller et al. (2008) \\
\hline LOC665542 & M & $\mathrm{X}$ & $9+$ & Mueller et al. (2008) \\
\hline Magea5 & M & $\mathrm{X}$ & 8 & Rogner et al. (1995) and Wang et al. (2005) \\
\hline MGC58426 & M & $X$ & 2 & Mueller et al. 2008 \\
\hline$N \times f 2$ & M & $\mathrm{X}$ & 1 & Herold et al. (2000) and Wang et al. (2005) \\
\hline Orly & M & $\mathrm{Y}$ & Many & Ellis et al. (2007) \\
\hline Ott & M & $X$ & 12 & Kerr et al. (1996) and Mueller et al. (2008) \\
\hline Pramel3 & M & $\mathrm{X}$ & 1 & Wang et al. (2005) \\
\hline Pramey & $\mathrm{C}$ & $\mathrm{Y}$ & $10+$ & Chang et al. (2011) \\
\hline Sat/1 & M & $\mathrm{X}$ & 1 & Ellis et al. (2005) \\
\hline Slxl1 & M & $\mathrm{X}$ & $14+$ & Ellis et al. (2005) and Reynard et al. (2007) \\
\hline Slx & M & $X$ & $25+$ & Calenda et al. (1994), Ellis et al. (2005), and Reynard et al. (2007) \\
\hline Sly & M & $\mathrm{Y}$ & Many & Ellis et al. (2005), Touré et al. (2005), and Reynard et al. (2009) \\
\hline Spanx & $\mathrm{H}$ & $\mathrm{X}$ & 10 & Westbrook et al. 2000 \\
\hline Sry & $\mathrm{H}, \mathrm{M}$ & $\mathrm{Y}$ & 1 & Sinclair et al. (1990) and Koopman et al. (1990) \\
\hline Ssty $1 / 2$ & M & $\mathrm{Y}$ & Many & Conway et al. (1994) and Touré et al. (2004) \\
\hline Ssxb & M & $X$ & $13+$ & Chen et al. (2003) and Mueller et al. (2008) \\
\hline Taf7l & M & $\mathrm{X}$ & 1 & Wang et al. $(2001,2005)$ \\
\hline Tex11 & M & $X$ & 1 & Wang et al. $(2001,2005)$ \\
\hline Tex16 & M & $\mathrm{X}$ & 1 & Wang et al. $(2001,2005)$ \\
\hline Tgif2/ $x 1$ & M & $\mathrm{X}$ & 2 & Blanco-Arias et al. (2002), Ellis et al. (2005), and Mueller et al. (2008) \\
\hline Tsga8 & M & $X$ & 1 & Taketo et al. (1997) and Uchida et al. (2000) \\
\hline Tspy & $\mathrm{R}$ & $\mathrm{Y}$ & 1 & Arnemann et al. (1991) and Kido \& Lau (2006) \\
\hline Ube2a & M & $\mathrm{X}$ & 1 & Koken et al. (1992) and Hendriksen et al. (1995) \\
\hline Ubelx & M & $\mathrm{X}$ & 1 & Imai et al. (1992) and Hendriksen et al. (1995) \\
\hline Ubely & M & $\mathrm{Y}$ & 1 & Mitchell et al. (1991), Kay et al. (1991), and Hendriksen et al. (1995) \\
\hline Usp9y & M & $\mathrm{Y}$ & 1 & Brown et al. (1998) and Wang et al. (2005) \\
\hline Vcy & $\mathrm{H}$ & $\mathrm{Y}$ & 2 & Lahn \& Page (2000) and Tse et al. (2003) \\
\hline Vsig1 & M & $\mathrm{X}$ & 1 & Ellis et al. (2005) \\
\hline Zfy & M & Y & 2 & Page et al. (1987) and Nagamine et al. (1990) \\
\hline Znf280by-as & $\mathrm{C}$ & $\mathrm{Y}$ & $130+$ & Yang et al. (2011) \\
\hline
\end{tabular}

C, cow; $H$, human; $M$, mouse; $R$, rat.

assume a conformation called post-meiotic sex chromatin (PMSC; Turner et al. 2006), which shares some of the same repressive histone marks, such as histone $\mathrm{H} 3$ dimethylated at lysine-9 (dimH3K9; Khalil et al. 2004). In contrast to the complete meiotic silencing of sex chromosome genes during MSUC, post-meiotic repression is incomplete (Mueller et al. 2008). The RNA polymerase excluded from the $X Y$ body at pachytene re-engages the $X$ and $Y$ chromosomes in round spermatids (Khalil et al. 2004), and multiple studies have reported the transcription of sex-linked genes in spermatids. Initially, sex-linked spermatid genes 
were identified as a by-product of other investigations, e.g. Zfy and Sry during the search for the sex-determining gene; Usp9y, Tspy, Daz, and Vcy during the characterisation of Y-linked genes conserved between human and rodents; and Akap4 and Spanx during the investigation of sperm proteins (Table 1). Hendriksen et al. (1995) carried out the first targeted investigation of sex chromosome transcription in spermatids, showing that the X-linked genes Ubelx and MHR6A (now known as Ube2a) and the Y-linked genes Ubely and Sry were highly transcribed in this cell type. Ube2a was also confirmed by northern blotting.

Recently, more systematic approaches have begun to unpick the full diversity of the post-meiotic sex chromosomal transcriptome. The investigation of mice with deletions on chromosome arm $\mathrm{Yq}$ (see Evidence for functional differences between haploid cells) identified the genetic complement of this region: Ssty1, Ssty2, Sly, Asty, and Orly, all of which are spermatid specific. A marked up-regulation of $X$-linked spermatid transcripts is also seen in the testes of these males, enabling the identification of several such genes (Ellis et al. 2005). Wang et al. (2005) examined a panel of 14 sex-linked genes known to be expressed in spermatogonia and showed that 13 of these genes showed some degree of post-meiotic reactivation. In particular, Tex11, Tex16, Taf7l, Pramel3, Nxf2, Magea5, Ube1y, and Usp9y showed the same mRNA levels in post-meiotic cells as in pre-meiotic cells. Most recently, Mueller et al. (2008) reported that, in mice, a collection of 33 multicopy X-linked gene families, representing $\sim 273$ individual gene copies, are expressed predominantly in spermatids. In addition, they showed low-level reactivation of many $X$-linked single-copy genes in round spermatids.

Collectively, the data indicate that for single-copy $X$ genes, post-meiotic repression is 'leaky'. This leakage appears to be context dependent, with single-copy genes showing reactivation in a variable proportion of round spermatids (up to $18 \%$ for $Z f x$ ). In contrast, the majority of multi-copy $X$ genes are active in the majority of $X$ spermatids. Mueller et al. (2008) propose that the copy number amplification of these genes is a downstream response to post-meiotic repression, allowing the transcription of critical post-meiotic sex-linked genes. An alternative hypothesis was formulated by Ellis et al. (2005) that the gene amplification on the mouse $X$ was a consequence of a genomic conflict between $X$ and $Y$ chromosomes (see also Evidence for functional differences between haploid cells). In support of this, the most highly ampliconic genes on the mouse became amplified shortly after Sly arose in the $\mathrm{Y}$ chromosome (Ellis et al. 2007, 2011). These hypotheses are not mutually exclusive: $S l y$, one of the participants in the proposed genomic conflict is believed to act via modulation of PMSC (Cocquet et al. 2009). The mechanism by which increased gene copy number leads to increased post-meiotic leakage is currently unclear.
It may be simply stochastic, with a higher copy number meaning a higher probability of at least one gene copy reactivating; alternatively, the repeat regions may fold into specialised structures such as hairpins or cruciforms and thereby evade the full extent of PMSC and the preceding MSUC.

The genes that have been confirmed by non-array methods as being transcribed post-meiotically are listed in Table 1. The criteria for inclusion in this list are either direct visualisation of nascent transcripts in spermatids by RNA FISH; or an increase in transcript expression in spermatids compared with spermatocytes, seen by RNA in situ hybridisation to testis slices or RT-PCR on separated cells; or increased transcription in testes with spermatids compared with testes without spermatids. This is thus a conservative list that explicitly excludes genes such as Hprt1 in which the transcript is present in the spermatids solely due to the presence of long-lived mRNAs transcribed pre-meiotically, but which is not actively transcribed in spermatids. Also excluded are genes such as Dby, Rps4y, and Smcy, in which the transcript and/or protein have been observed in haploid cells, but retention of pre-meiotic transcripts has not been excluded.

Confirmation of post-meiotic expression is largely confined to the mouse at present, as while many sexlinked genes are known to be germ cell specific in human, few human studies have investigated the stagespecific localisation of $X / Y$ transcripts, and still fewer studies have been performed in farm animal species. The functions of the genes that escape post-meiotic repression are largely unknown. Akap4 is a flagellar protein expressed solely in post-meiotic spermatid cells and is essential for the development of all sperm as a component of the fibrous sheath and as a scaffolding protein for the regulatory proteins in the flagella of spermatozoa (Miki et al. 2002). Cypt and Spanx genes may have roles in acrosomal development, and Sly is a regulator of PMSC. $S / x$, the multi-copy $X$-linked homologue of $S / y$, is exclusively expressed in spermatids as confirmed by RNA FISH (Reynard et al. 2007), and siRNA knockdown of S/x family members has significant effects on sperm head morphology (Cocquet et al. 2010).

\section{Evidence for functional differences between haploid cells}

Compelling evidence for biochemical differences between individual sperm is provided by certain examples of transmission ratio distortion (TRD), in which there is a non-Mendelian inheritance pattern in the offspring of males heterozygous for a given genetic variant. In principle, TRD may arise meiotically (affecting chromosome segregation), post-meiotically (affecting spermatid maturation and fertilising ability), or post-fertilisation (affecting embryo viability). Distorter 
genes falling into the second category exert their effects by producing a functional difference between haploid cells with and without the distorter: the gene products encoded by such distorters must, therefore, either be shared unevenly between sister spermatids or interact with other factors that are not shared. Such distorters are most commonly studied in non-mammalian model species such as Drosophila (Tao et al. 2007); however, there are three known mammalian examples. In each, normal and mutant sperm are produced in equal ratios and normal/mutant embryo survival is unaffected, but there is nevertheless skewed inheritance, demonstrating that the TRD must be due to functional differences between normal and mutant sperm.

Genes in the $t$ complex are the most well-known and best characterised distorters in mammals. The $t$ complex is a variant region of mouse chromosome 17 characterised by large-scale inversions that suppress recombination between $t$ and normal haplotypes, thus preserving an association between several distorter genes and a single responder gene, which collaboratively lead to TRD (Lyon 2003). The identities of the distorter genes are unknown; however, the responder has been identified as an aberrant kinase fusion gene, $T_{c} r^{\text {Smok }}$ (Herrmann et al. 1999). Another example of TRD involving sperm functional heterogeneity concerns Robertsonian translocations involving mouse chromosome 6. Males heterozygous for $\mathrm{Rb}(6.16)$ and $\mathrm{Rb}(6.15)$ translocations transmit almost exclusively euploid gametes resulting from alternate segregation, with very little transmission of aneuploid adjacent segregants. Within the euploid gamete population, the normal (non-translocated) chromosome complement transmits at an increased rate relative to the balanced translocation during natural mating. If aged sperm is used for fertilisation by housing the male apart from the female for 14 days, the TRD is abolished, thus indicating that equal numbers of balanced/normal sperm are produced and that their relative fertilising ability depends on the intercoital interval (Aranha \& Martin-DeLeon 1995). There is also no TRD when IVF is performed using sperm from carrier males. More interestingly, these mouse models also exhibit a sex ratio skew in favour of males during natural mating, which is also abolished in aged sperm and in IVF. This first indicates that there must be some functional asymmetry between $X$ and $Y$ sperm which, if identified, could form the basis for sperm selection; and secondly that this $\mathrm{X} / \mathrm{Y}$ asymmetry interacts with the chromosome 6 complement of any given sperm.

Most interesting of all with regard to sperm selection is the sex ratio skewing seen in the offspring of mice bearing partial deletions on the long arm of the $Y$ chromosome (Conway et al. 1994). Males with smaller deletions on $\mathrm{Yq}(\sim 2 / 3$ of the long arm deleted) show mild sperm head abnormalities and a sex ratio skew in favour of females, while larger deletions lead to more severe head shape abnormalities and sterility (Touré et al. 2004). ICSI using sperm from Yq-deleted males yields a balanced sex ratio, indicating that the skew does not show decreased differential gamete production or increased embryonic death, but must result from differential fertilising ability of $X$ and $Y$ sperm (Ward \& Burgoyne 2006). In this model, $Y q$ deletion leads to decreased transcript levels of multi-copy Yq-linked genes and increased transcription of $X$-linked and Yp-linked genes (Ellis et al. 2005, Touré et al. 2005). It has recently been shown that $S / y$, one of the Yq-linked genes affected by the deletion, is a regulator of PMSC (see Sex chromosome transcriptional activity in spermatids), and Sly deficiency leads to the up-regulation of other sex-linked genes in the spermatids of affected males (Cocquet et al. 2009). The association of increased $X$ transcription with increased $X$ transmission is strongly suggestive of a genomic conflict between $X$ and $Y$ chromosomes, i.e. one or more genes on the $X$ chromosome constitutes the distorter gene(s) responsible for increased X chromosome transmission, and Sly acts to repress the distorter(s) and restore a normal sex ratio.

As discussed in Box 1, the functional differences between the sperm that underlie TRD depend on a lack of transcript sharing between sister spermatids. This has been observed for both the $t$ complex, in which the $\mathrm{TCr}^{\text {Smok }}$ responder was recently shown not to be shared between syncytial spermatids (Véron et al. 2009), and the chromosome 6 models, in which the transmission ratio skew appears to be due to non-sharing of allelically distinct variants of the Spam1 hyaluronidase gene (Zheng et al. 2001, Martin-Deleon et al. 2005). The genes responsible for the sex ratio skew in Yq-deleted males and/or the sex ratio skew in the Robertsonian fusion models remain to be identified; however, they are predicted to be encoded by the sex chromosomes and to escape transcript sharing. In addition to compartmentalisation of the transcripts, the resulting protein products must also escape sharing, for example by immediate insertion into the cell membrane (e.g. Spam1) or incorporation into a non-diffusible protein complex (e.g. insertion of $T_{C r} r^{\text {Smok }}$ into the flagellum).

\section{Transcriptional and translational activity in spermatozoa}

Unlike sperm mitochondria, which remain transcriptionally competent, mature sperm nuclei have historically been believed to be transcriptionally inert due to the repackaging of chromatin with protamines, leaving it inaccessible for transcription. Despite this, it is increasingly clear that some regions of the sperm genome remain packaged by histones rather than proteins (reviewed in Miller et al. (2010)), either as conventional nucleosomes or in novel nucleosome-like structures that organise non-standard lengths of DNA (Govin et al. 2007). It is likely that this less-condensed portion of the 
sperm genome, the nucleohistone fraction, primes specific genes for early reactivation during embryogenesis, but it is also possible that it is permissive for transcription in sperm. No nuclear gene has yet been shown to be transcribed in sperm; however, RNA polymerase II is known to be present and associated with the Hspa1b promoter in mouse epididymal sperm (Wilkerson \& Sarge 2009).

A further factor affecting transcriptional competence of sperm chromatin is the activity of 'selfish' genomic elements such as retroposons. The sperm nucleohistone fraction is enriched for retroposons (Pittoggi et al. 1999), reverse transcriptase activity encoded by such retroposons has been observed in sperm nuclei of several species (e.g. Fuster et al. 1977), and reverse transcriptase molecules can be directly visualised in association with the sperm nuclear scaffold by immunogold staining (Giordano et al. 2000). Moreover, the nucleohistone fraction is preferentially targeted for incorporation of exogenous DNA during sperm-mediated gene transfer (Smith \& Spadafora 2005). Collectively, these results imply active transcription of retroposons in sperm and that these parasitic genomic elements are able to maintain regions of the sperm genome in a transcriptionally competent state in order to facilitate their own transmission during late spermatogenesis. In this light, it is interesting to note that the $X$ chromosome is enriched for full-length actively proliferating LINE elements and is thus a potential location for continued transcription in mature sperm.

Transcription in sperm cannot lead to an antigenic difference unless the transcripts are translated. A radiolabeling study has indicated that spermatozoa are indeed translationally active and incorporate labelled amino acids $\left(\left[{ }^{35} \mathrm{~S}\right]\right.$ methionine, $\left[{ }^{35} \mathrm{~S}\right]$ cysteine and BODIPY-lysine-tRNA ${ }^{\text {Lys }}$ ) into newly synthesised polypeptides during capacitation (Gur \& Breitbart 2006). The incorporation is completely inhibited by mitochondrial translation inhibitor $\mathrm{D}$-chloramphenicol (CP) but not by the cytoplasmic translation inhibitor cycloheximide. Moreover, 55S mitochondrial ribosomes were present in polysomal fractions and $80 \mathrm{~S}$ cytoplasmic ribosomes were not, indicating that translation in sperm utilises mitochondrial ribosomes. Intriguingly, CP treatment lowered the levels of a number of nuclear-encoded proteins in sperm, suggesting that the mitochondrial ribosomes translate nuclear transcripts in addition to mitochondrial transcripts. This translation is most likely to utilise stored spermatozoal RNAs retained following cytoplasmic shedding, for which there is now a large and growing body of evidence (reviewed in Lalancette et al. (2008) and Dadoune (2009)). The current belief is that the stored mRNA either represents non-functional remnants from earlier spermatid stages or a paternal contribution to early embryonic events. Evidence for the latter is given by a recent study showing that Dby mRNA is retained in mature mouse sperm and that injection of an interfering antisense RNA into the male pronucleus (but not the female pronucleus) disrupts zygotic development (Yao et al. 2010). Evidence for a potential role in sperm function is given by Gur \& Breitbart (2006), which showed that CP treatment significantly altered sperm parameters including motility, capacitation and fertilisation rate: this may alternatively reflect disruption of sperm mitochondrial function rather than dependence on ongoing translation of nuclear genes by nuclear ribosomes.

\section{The ongoing search for OSSAs}

Current searches for OSSAs have tended to follow one of three approaches: they take a single-transcript approach and test to see whether an expression of a selected sex-linked gene is specific to $X$ or $Y$ sperm, a proteomic approach screening for differentially expressed proteins, or the immunological approach of raising antibodies to mixed sperm proteins and testing for specificity. To date, all the three approaches have failed: the first due to insufficient throughput and the probability in selecting the correct candidate gene and the latter two due to the signal/noise ratio trying to discern a single OSSA from hundreds if not thousands of antigenic sperm surface proteins.

Initial candidate gene work focused on the $\mathrm{H}-\mathrm{Y}$ antigens, a collection of male-specific minor histocompatibility antigens encoded by $Y$ chromosomal proteins. $\mathrm{H}-\mathrm{Y}$ epitopes encoded by Smcy have been shown to be present on the plasma membrane over the sperm head and midpiece (Bradley et al. 1987). Subsequent work shows that the levels on $X$ and $Y$ sperm are similar and that this gene is not a candidate for immunoselection (Sills et al. 1998). As subsequent work elucidated the gene content of the $\mathrm{Y}$ chromosome gene content, various studies (Table 1) investigated the expression of Y-borne genes and their $X$ homologues in spermatids; however, none has as yet been found to be differentially expressed. Very few other $X$-linked genes, i.e. those without $Y$ homologues, have been tested as candidate OSSAs. In the Ellis et al. (2005) study, RNA in situ for H2al1, Gmcl1I, S/x, S/xl1, and Vsig1 showed a signal in all round spermatids at a given tubule stage, but this does not rule out more subtle dosage differences, translational differences or continuation of transcription into latestage spermatids after breakage of the cytoplasmic bridges. Yeh et al. (2005) claim that ESX1 antiserum stains approximately half the sperm population, whereas SRY antiserum shows a mutually exclusive staining pattern. Since transcripts of Esx1 are known to be present in all spermatids (Branford et al. 1997), this is compatible with models B-F for OSSA generation (see Box 1). While the study is suggestive that ESX1 and SRY may constitute OSSAs, it did not directly test whether the ESX-positive sperm carry an X chromosome or whether the SRY-positive sperm carry a Y chromosome. Thus, it is 
possible that ESX1 and SRY are markers for different sperm populations but that this does not correlate with their X/Y-bearing status. Moreover, the translational status of SRY in mouse germ cells is highly disputed, since the spermatid transcripts are circular (Dolci et al. 1997) and hence lack necessary translational signals. It is thus likely that SRY antiserum used in this study is detecting some other antigen in sperm. If the findings can be confirmed and ESX1 does prove to be a true OSSA, it is nevertheless unlikely to be amenable for use in sperm separation because its epitope is within the nucleus rather than in the plasma membrane. Nevertheless, this provides an interesting demonstration of functional heterogeneity in the sperm population that opens the way for a more systematic search for OSSAs.

Two proteomic studies have used flow-sorted $X$ and $Y$ sperm populations to look for protein differences using a range of techniques, also with limited success. Twodimensional electrophoresis of pig sperm proteins did not reveal any qualitative or quantitative difference in protein spots between $X$ and $Y$ sperm (Hendriksen et al. 1996). The same negative result was found for bull $X$ and $Y$ sperm surface membranes using one-dimensional SDS-PAGE (Howes et al. 1997). Encouragingly, the latter study did detect a group of proteins at $\sim 40 \mathrm{kDa}, 5.3 \mathrm{pl}$ using two-dimensional electrophoresis that appeared to be enriched in X-bearing sperm. These proteins were detected in whole sperm extract but not in a membraneenriched sample, suggesting that they are not surface antigens and thus unsuitable for sperm sorting. Proteomic screening studies are usually limited to the abundant proteins present in any given sample, although the advent of mass screening via mass spectrometry is changing this, and are also subjected to other considerations such as solubility, proteolysis, etc.

The immunological approach was first used by Blecher et al. (1999), who focused on SCSPs, i.e. proteins encoded by sex-linked transcripts. They argued that Ohno's law (Ohno 1967) dictates that SCSPs should be more highly conserved than other proteins, and that therefore: a) immunisation of rabbits with same-sex mixed bovine tissue would not raise antibodies to SCSPs since these would be conserved enough to be recognised as 'self', allowing immunopurification of putative SCSPs; and b) subsequent immunisation of male rabbits with the putative $X$-linked SCSPs and female rabbits with the putative $\mathrm{Y}$-linked SCSPs would generate $\mathrm{X}$ - and $\mathrm{Y}$-specific antisera. The underlying rationale is flawed on two grounds: first, both reproductive and Y-linked genes are known to evolve much faster than other categories of gene, undermining the 'SCSP conservation' hypothesis. Secondly, male rabbits $(X Y)$ still possess an $X$ chromosome and will, therefore, not selectively raise anti-Xantisera. Nevertheless, this study is noteworthy for directly testing whether it was possible to manipulate offspring sex by this method, reporting a partially successful enrichment for male IVF embryos in antimale antibody-selected $(66 \%$ male, $6 \%$ female, and $28 \%$ untypeable) relative to control sperm samples $(55 \%$ male, $28 \%$ female, and $17 \%$ untypeable). This suggests that there may be conserved cell surface proteins on bovine $Y$ spermatozoa that are immunogenic in female rabbits but not in male rabbits. More recently, phage selection was used to generate a library of monoclonal antibodies recognising sperm surface proteins (Soares \& Barbosa 2008). Twenty-four clones that each bound $40-60 \%$ of spermatozoa were then tested for their ability to bind male and female leukocytes, and one clone was found to bind only to male cells. Collectively, these results demonstrate functional heterogeneity in the sperm population, but as with Yeh et al. (2005), these findings once again fall short of demonstrating that the sperm recognised by the putative male-specific antigen are in fact Y-bearing sperm. Most recently of all, Sang et al. (2011). carried out a more rigorous version of the Blecher approach, generating rabbit antisera against flow-separated $X$ and $Y$ bovine sperm and subsequently using immunoprecipitation to remove cross-reacting antibodies. This study reports the presence of an $\sim 30 \mathrm{kDa}$ OSSA in X-bearing bovine sperm: it will be interesting to determine whether this is related to the group of $\sim 40$ kDa OSSAs observed by Howes et al. (1997).

\section{Conclusion: where next?}

Haploid spermatids harbour a diverse transcriptome and remain translationally competent throughout the mature sperm stage. This diversity is not uniformly expressed but is variable between individual cells and categories of cells, as shown by various functional/immunological studies of sperm antigens. There are consistent functional differences between $X$ and $Y$ sperm, as shown by examples of sex ratio skewing in the offspring of mutant males, and the mechanisms by which transcript compartmentalisation contributes to sperm functional heterogeneity are beginning to be investigated. To date, the search for OSSAs associated with these differences has been fruitless, although the immunological approach has shown some promise.

As we argue above in Box 1, we believe that any functional difference between $X$ and $Y$ sperm will ultimately be traceable to a difference in their transcriptional content. DNA microarray technology is now a sufficiently mature technology that robust, genome-wide screening can be performed on very small amounts of starting material such as flow-sorted cells. A full investigation of transcriptional differences between flow-sorted $\mathrm{X}$ - and Y-bearing round spermatids, elongating spermatids, condensing spermatids and mature sperm would potentially allow the selection of strong candidate genes for subsequent immunological testing as suitable antigens for sperm sorting. These could then be prioritised based on their protein domain structure and the likelihood that they will be exposed on the 
plasma membrane. Additionally, as proteomic technologies continue to improve and more complete coverage of the proteome is obtained, studies on separated X- and Y-bearing cells will continue to be of great interest in this regard. Another promising avenue for investigation would be a systematic chromatin immunoprecipitation analysis of the regions bound by RNA polymerase II in mature spermatozoa: these regions may potentially remain transcriptionally competent following the breakage of the cytoplasmic bridges. Finally, continued analysis of known sex ratio distortion phenotypes in mouse and other animal models will reveal naturally occurring modifiers of sex ratio, which may in turn be amenable to commercial development.

\section{Declaration of interest}

The authors declare that there is no conflict of interest that could be perceived as prejudicing the impartiality of the research reported.

\section{Funding}

P J I Ellis was funded by the BBSRC (grant number BB/F007434/1). Y Yu and S Zhang were supported by Chinese projects (S2010GR0947, 2010DFA31820, 2009ZX08009142B, 2011ZX08007-003, and 2010-Z16), Hubei project (YJH0044) and Wuhan projects (201171034317 and 201070934339).

\section{Acknowledgements}

We thank Dr Ben Skinner for assistance in preparing the figures for this review.

\section{References}

Aranha IP \& Martin-DeLeon PA 1995 Mouse chromosome 6 in $\mathrm{Rb}$ translocations: consequences in singly and doubly heterozygous males. Cytogenetics and Cell Genetics 69 253-259. (doi:10.1159/000133975)

Arnemann J, Jakubiczka S, Thüring S \& Schmidtke J 1991 Cloning and sequence analysis of a human Y-chromosome-derived, testicular cDNA, TSPY. Genomics 11 108-114. (doi:10.1016/0888-7543(91)90107-P)

Beernink FJ, Dmowski WP \& Ericsson RJ 1993 Sex preselection through albumin separation of sperm. Fertility and Sterility 59 382-386.

Blanco-Arias P, Sargent CA \& Affara NA 2002 The human-specific Yp11.2/Xq21.3 homology block encodes a potentially functional testisspecific TGIF-like retroposon. Mammalian Genome 13 463-468. (doi:10.1007/s00335-002-3010-9)

Blecher SR, Howie R, Li S, Detmar J \& Blahut LM 1999 A new approach to immunological sexing of sperm. Theriogenology 52 1309-1321. (doi:10. 1016/S0093-691X(99)00219-8)

Bradley MP 1989 Immunological sexing of mammalian semen: current status and future options. Journal of Dairy Science 72 3372-3380. (doi:10.3168/jds.S0022-0302(89)79500-X)

Bradley MP, Forrester IT \& Heslop BF 1987 Identification of a male-specific $(\mathrm{H}-\mathrm{Y})$ antigen on the flagellar plasma membrane of ram epididymal spermatozoa. Human Genetics 75 362-367. (doi:10.1007/BF00284109)

Branford WW, Zhao GQ, Valerius MT, Weinstein M, Birkenmeier EH, Rowe LB \& Potter SS 1997 Spx1, a novel X-linked homeobox gene expressed during spermatogenesis. Mechanisms of Development 65 87-98. (doi:10.1016/S0925-4773(97)00058-0)
Braun RE, Behringer RR, Peschon JJ, Brinster RL \& Palmiter RD 1989 Genetically haploid spermatids are phenotypically diploid. Nature 337 373-376. (doi:10.1038/337373a0)

Breucker H, Schäfer E \& Holstein AF 1985 Morphogenesis and fate of the residual body in human spermiogenesis. Cell and Tissue Research 240 303-309. (doi:10.1007/BF00222339)

Brown AL \& Kay GF 1999 Bex1, a gene with increased expression in parthenogenetic embryos, is a member of a novel gene family on the mouse X chromosome. Human Molecular Genetics 8 611-619. (doi:10. 1093/hmg/8.4.611)

Brown GM, Furlong RA, Sargent CA, Erickson RP, Longepied G, Mitchell M, Jones MH, Hargreave TB, Cooke HJ \& Affara NA 1998 Characterisation of the coding sequence and fine mapping of the human $D F F R Y$ gene and comparative expression analysis and mapping to the Sxrb interval of the mouse $\mathrm{Y}$ chromosome of the Dffry gene. Human Molecular Genetics 7 97-107. (doi:10.1093/hmg/7.1.97)

Caldwell KA \& Handel MA 1991 Protamine transcript sharing among postmeiotic spermatids. PNAS 88 2407-2411. (doi:10.1073/pnas.88.6. 2407)

Calenda A, Allenet B, Escalier D, Bach JF \& Garchon HJ 1994 The meiosisspecific $X m r$ gene product is homologous to the lymphocyte XIr protein and is a component of the XY body. EMBO Journal 13 100-109.

Carrera A, Gerton GL \& Moss SB 1994 The major fibrous sheath polypeptide of mouse sperm: structural and functional similarities to the A-kinase anchoring proteins. Developmental Biology 165 272-284. (doi:10.1006/dbio.1994.1252)

Chang TC, Yang Y, Yasue H, Bharti AK, Retzel EF \& Liu WS 2011 The expansion of the PRAME gene family in Eutheria. PLOS ONE 6 e16867. (doi:10.1371/journal.pone.0016867)

Chen MJ, Guu HF \& Ho ES 1997 Efficiency of sex pre-selection of spermatozoa by albumin separation method evaluated by doublelabelled fluorescence in-situ hybridization. Human Reproduction 12 1920-1926. (doi:10.1093/humrep/12.9.1920)

Chen YT, Alpen B, Ono T, Gure AO, Scanlan MA, Biggs WH III, Arden K, Nakayama E \& Old LJ 2003 Identification and characterization of mouse SSX genes: a multigene family on the $X$ chromosome with restricted cancer/testis expression. Genomics 82 628-636. (doi:10.1016/S08887543(03)00183-6)

Cocquet J, Ellis PJ, Yamauchi Y, Mahadevaiah SK, Affara NA, Ward MA \& Burgoyne PS 2009 The multicopy gene Sly represses the sex chromosomes in the male mouse germline after meiosis. PLoS Biology 7 e1000244. (doi:10.1371/journal.pbio.1000244)

Cocquet J, Ellis PJ, Yamauchi Y, Riel JM, Karacs TP, Rattigan A, Ojarikre OA, Affara NA, Ward MA \& Burgoyne PS 2010 Deficiency in the multicopy Sycp3-like X-linked genes $S / x$ and $S / x / 1$ causes major defects in spermatid differentiation. Molecular Biology of the Cell 21 3497-3505. (doi:10.1091/mbc.E10-07-0601)

Conway SJ, Mahadevaiah SK, Darling SM, Capel B, Rattigan AM \& Burgoyne PS 1994 Y353/B: a candidate multiple-copy spermiogenesis gene on the mouse $\mathrm{Y}$ chromosome. Mammalian Genome 5 203-210. (doi:10.1007/BF00360546)

Dadoune JP 2009 Spermatozoal RNAs: what about their functions? Microscopy Research and Technique 72 536-551. (doi:10.1002/jemt. 20697)

Dolci S, Grimaldi P, Geremia R, Pesce M \& Rossi P 1997 Identification of a promoter region generating Sry circular transcripts both in germ cells from male adult mice and in male mouse embryonal gonads. Biology of Reproduction 57 1128-1135. (doi:10.1095/biolreprod57.5.1128)

Dym M \& Fawcett DW 1971 Further observations on the numbers of spermatogonia, spermatocytes, and spermatids connected by intercellular bridges in the mammalian testis. Biology of Reproduction 4 195-215.

Ellis PJ, Clemente EJ, Ball P, Touré A, Ferguson L, Turner JM, Loveland KL, Affara NA \& Burgoyne PS 2005 Deletions on mouse $\mathrm{Yq}$ lead to upregulation of multiple $\mathrm{X}$ - and Y-linked transcripts in spermatids. Human Molecular Genetics 14 2705-2715. (doi:10.1093/hmg/ddi304)

Ellis PJ, Ferguson L, Clemente EJ \& Affara NA 2007 Bidirectional transcription of a novel chimeric gene mapping to mouse chromosome Yq. BMC Evolutionary Biology 7 171. (doi:10.1186/1471-2148-7-171)

Ellis PJI, Bacon J \& Affara NA 2011 Association of Sly with sex-linked gene amplification during mouse evolution: a side effect of genomic conflict in spermatids? Human Molecular Genetics 20 3010-3021. (doi:10.1093/ hmg/ddr204) 
Ferguson L, Ellis PJ \& Affara NA 2009 Two novel mouse genes mapped to chromosome $\mathrm{Yp}$ are expressed specifically in spermatids. Mammalian Genome 20 193-206. (doi:10.1007/s00335-009-9175-8)

Fuster CD, Farrell D, Stern FA \& Hecht NB 1977 RNA polymerase activity in bovine spermatozoa. Journal of Cell Biology 74 698-706. (doi:10. 1083/jcb.74.3.698)

Giordano R, Magnano AR, Zaccagnini G, Pittoggi C, Moscufo N, Lorenzini R \& Spadafora C 2000 Reverse transcriptase activity in mature spermatozoa of mouse. Journal of Cell Biology 148 1107-1113. (doi:10. 1083/jcb.148.6.1107)

Gledhill BL 1988 Selection and separation of X- and Y- chromosomebearing mammalian sperm. Gamete Research 20 377-395. (doi:10. 1002/mrd.1120200312)

Govin J, Escoffier E, Rousseaux S, Kuhn L, Ferro M, Thevenon J, Catena R, Davidson I, Garin J, Khochbin S et al. 2007 Pericentric heterochromatin reprogramming by new histone variants during mouse spermiogenesis. Journal of Cell Biology 176 283-294. (doi:10.1083/ jcb.200604141)

Guo GQ \& Zheng GC 2004 Hypotheses for the functions of intercellular bridges in male germ cell development and its cellular mechanisms. Journal of Theoretical Biology 229 139-146. (doi:10.1016/j.jtbi.2004. 03.010)

Gur Y \& Breitbart H 2006 Mammalian sperm translate nuclear-encoded proteins by mitochondrial-type ribosomes. Genes and Development 20 411-416. (doi:10.1101/gad.367606)

Habermann B, Mi HF, Edelmann A, Bohring C, Bäckert IT, Kiesewetter F, Aumüller G \& Vogt PH 1998 DAZ (deleted in Azoospermia) genes encode proteins located in human late spermatids and in sperm tails. Human Reproduction 13 363-369. (doi:10.1093/humrep/13.2.363)

Hansen MA, Nielsen JE, Tanaka M, Almstrup K, Skakkebaek NE \& Leffers H 2006 Identification and expression profiling of 10 novel spermatid expressed CYPT genes. Molecular Reproduction and Development 73 568-579. (doi:10.1002/mrd.20463)

Hendriksen PJ 1999 Do $X$ and $Y$ spermatozoa differ in proteins? Theriogenology 52 1295-1307. (doi:10.1016/S0093-691X(99)00218-6)

Hendriksen PJ, Hoogerbrugge JW, Themmen AP, Koken $\mathrm{MH}$, Hoeijmakers JH, Oostra BA, van der Lende T \& Grootegoed JA 1995 Postmeiotic transcription of $\mathrm{X}$ and $\mathrm{Y}$ chromosomal genes during spermatogenesis in the mouse. Developmental Biology 170 730-733. (doi:10.1006/dbio.1995.1252)

Hendriksen PJ, Welch GR, Grootegoed JA, Van der Lende T \& Johnson LA 1996 Comparison of detergent-solubilized membrane and soluble proteins from flow cytometrically sorted X- and Y-chromosome bearing porcine spermatozoa by high resolution 2-D electrophoresis. Molecular Reproduction and Development 45 342-350. (doi:10.1002/(SICl)10982795(199611)45:3<342::AID-MRD11>3.0.CO;2-0)

Herold A, Suyama M, Rodrigues JP, Braun IC, Kutay U, Carmo-Fonseca M, Bork P \& Izaurralde E 2000 TAP (NXF1) belongs to a multigene family of putative RNA export factors with a conserved modular architecture. Molecular and Cellular Biology 20 8996-9008. (doi:10.1128/MCB.20. 23.8996-9008.2000)

Herrmann BG, Koschorz B, Wertz K, McLaughlin KJ \& Kispert A 1999 A protein kinase encoded by the $t$ complex responder gene causes nonMendelian inheritance. Nature 402 141-146. (doi:10.1038/45970)

Hossain AM, Barik S \& Kulkarni PM 2001 Lack of significant morphological differences between human $X$ and $Y$ spermatozoa and their precursor cells (spermatids) exposed to different prehybridization treatments. Journal of Andrology 22 119-123.

Howes EA, Miller NG, Dolby C, Hutchings A, Butcher GW \& Jones R 1997 A search for sex-specific antigens on bovine spermatozoa using immunological and biochemical techniques to compare the protein profiles of $X$ and $Y$ chromosome-bearing sperm populations separated by fluorescence-activated cell sorting. Journal of Reproduction and Fertility 110 195-204. (doi:10.1530/jrf.0.1100195)

Imai N, Kaneda S, Nagai Y, Seno T, Ayusawa D, Hanaoka F \& Yamao F 1992 Cloning and sequence of a functionally active CDNA encoding the mouse ubiquitin-activating enzyme E1. Gene 118 279-282. (doi:10. 1016/0378-1119(92)90200-9)

Kaneko S, Yamaguchi J, Kobayashi T \& lizuka R 1983 Separation of human $\mathrm{X}$ - and Y-bearing sperm using percoll density gradient centrifugation. Fertility and Sterility 40 661-665.
Kay GF, Ashworth A, Penny GD, Dunlop M, Swift S, Brockdorff N \& Rastan S 1991 A candidate spermatogenesis gene on the mouse $Y$ chromosome is homologous to ubiquitin-activating enzyme E1. Nature 354 486-489. (doi:10.1038/354486a0)

Kerr SM, Taggart MH, Lee M \& Cooke HJ 1996 Ott, a mouse X-linked multigene family expressed specifically during meiosis. Human Molecular Genetics 5 1139-1148. (doi:10.1093/hmg/5.8.1139)

Khalil AM, Boyar FZ \& Driscoll DJ 2004 Dynamic histone modifications mark sex chromosome inactivation and reactivation during mammalian spermatogenesis. PNAS 101 16583-16587. (doi:10.1073/pnas.0406 325101)

Kido T \& Lau YF 2006 The rat Tspy is preferentially expressed in elongated spermatids and interacts with the core histones. Biochemical and Biophysical Research Communications 350 56-67. (doi:10.1016/j. bbrc.2006.08.191)

Kierszenbaum AL \& Tres LL 1974 Nucleolar and perichromosomal RNA synthesis during meiotic prophase in the mouse testis. Journal of Cell Biology 60 39-53. (doi:10.1083/jcb.60.1.39)

Kleene KC 2003 Patterns, mechanisms, and functions of translation regulation in mammalian spermatogenic cells. Cytogenetic and Genome Research 103 217-224. (doi:10.1159/000076807)

Kleiman SE, Yogev L, Hauser R, Botchan A, Bar-Shira Maymon B, Schreiber L, Paz G \& Yavetz H 2003 Members of the CDY family have different expression patterns: CDY1 transcripts have the best correlation with complete spermatogenesis. Human Genetics 113 486-492. (doi:10. 1007/s00439-003-0990-9)

Koken MH, Smit EM, Jaspers-Dekker I, Oostra BA, Hagemeijer A, Bootsma D \& Hoeijmakers JH 1992 Localization of two human homologs, HHR6A and HHR6B, of the yeast DNA repair gene RAD6 to chromosomes Xq24-q25 and 5q23-q31. Genomics 12 447-453. (doi:10.1016/0888-7543(92)90433-S)

Koopman P, Munsterberg A, Capel B, Vivian N \& Lovell-Badge R 1990 Expression of a candidate sex-determining gene during mouse testis differentiation. Nature 348 450-452. (doi:10.1038/348450a0)

Lahn BT \& Page DC 1999 Retroposition of autosomal mRNA yielded testisspecific gene family on human Y chromosome. Nature Genetics 21 429-433. (doi:10.1038/7771)

Lahn BT \& Page DC 2000 A human sex-chromosomal gene family expressed in male germ cells and encoding variably charged proteins. Human Molecular Genetics 9 311-319. (doi:10.1093/hmg/9.2.311)

Lalancette C, Miller D, Li Y \& Krawetz SA 2008 Paternal contributions: new functional insights for spermatozoal RNA. Journal of Cellular Biochemistry 104 1570-1579. (doi:10.1002/jcb.21756)

Li Y, Lemaire P \& Behringer RR 1997 Esx1, a novel X chromosome-linked homeobox gene expressed in mouse extraembryonic tissues and male germ cells. Developmental Biology 188 85-95. (doi:10.1006/dbio.1997.8640)

Lyon MF 2003 Transmission ratio distortion in mice. Annual Review of Genetics 37 393-408. (doi:10.1146/annurev.genet.37.110801.143030)

Martin-DeLeon PA, Zhang H, Morales CR, Zhao Y, Rulon M, Barnoski BL, Chen H \& Galileo DS 2005 Spam1-associated transmission ratio distortion in mice: elucidating the mechanism. Reproductive Biology and Endocrinology 3 32. (doi:10.1186/1477-7827-3-32)

McKee BD \& Handel MA 1993 Sex chromosomes, recombination, and chromatin conformation. Chromosoma 102 71-80. (doi:10.1007/ BF00356023)

Miki K, Willis WD, Brown PR, Goulding EH, Fulcher KD \& Eddy EM 2002 Targeted disruption of the Akap4 gene causes defects in sperm flagellum and motility. Developmental Biology 248 331-342. (doi:10.1006/dbio. 2002.0728)

Miller D, Brinkworth M \& Iles D 2010 Paternal DNA packaging in spermatozoa: more than the sum of its parts? DNA, histones, protamines and epigenetics Reproduction 139 287-301. (doi:10.1530/REP-09-0281)

Mitchell MJ, Woods DR, Tucker PK, Opp JS \& Bishop CE 1991 Homology of a candidate spermatogenic gene from the mouse $Y$ chromosome to the ubiquitinactivating enzyme E1. Nature 354 483-486. (doi:10.1038/354483a0)

Moss SB, VanScoy H \& Gerton GL 1997 Mapping of a haploid transcribed and translated sperm-specific gene to the mouse $X$ chromosome. Mammalian Genome 8 37-38. (doi:10.1007/s003359900342)

Mueller JL, Mahadevaiah SK, Park PJ, Warburton PE, Page DC \& Turner JM 2008 The mouse $X$ chromosome is enriched for multicopy testis genes showing postmeiotic expression. Nature Genetics 40 794-799. (doi:10. 1038/ng.126) 
Nagamine CM, Chan K, Hake LE \& Lau YF 1990 The two candidate testisdetermining $Y$ genes ( $Z f y-1$ and $Z f y-2)$ are differentially expressed in fetal and adult mouse tissues. Genes and Development 4 63-74. (doi:10. 1101/gad.4.1.63)

Ohno S 1967 Sex chromosomes and sex-linked genes. Berlin: Springer-Verlag.

Page DC, Mosher R, Simpson EM, Fisher EM, Mardon G, Pollack J, McGillivray B, de la Chapelle A \& Brown LG 1987 The sex-determining region of the human $\mathrm{Y}$ chromosome encodes a finger protein. Cell $\mathbf{5 1}$ 1091-1104. (doi:10.1016/0092-8674(87)90595-2)

Penfold LM, Holt C, Holt WV, Welch GR, Cran DG \& Johnson LA 1998 Comparative motility of $\mathrm{X}$ and $\mathrm{Y}$ chromosome-bearing bovine sperm separated on the basis of DNA content by flow sorting. Molecular Reproduction and Development 50 323-327. (doi:10.1002/(SICI)10982795(199807)50:3 <323::AID-MRD8 > 3.0.CO;2-L)

Pittoggi C, Renzi L, Zaccagnini G, Cimini D, Degrassi F, Giordano R, Magnano AR, Lorenzini R, Lavia P \& Spadafora C 1999 A fraction of mouse sperm chromatin is organized in nucleosomal hypersensitive domains enriched in retroposon DNA. Journal of Cell Science 112 3537-3548.

Rath D, Moench-Tegeder G, Taylor U \& Johnson LA 2009 Improved quality of sex-sorted sperm: a prerequisite for wider commercial application. Theriogenology 71 22-29. (doi:10.1016/j.theriogenology.2008.09.027)

Reijo R, Lee TY, Salo P, Alagappan R, Brown LG, Rosenberg M, Rozen S, Jaffe T, Straus D, Hovatta O et al. 1995 Diverse spermatogenic defects in humans caused by $\mathrm{Y}$ chromosome deletions encompassing a novel RNA-binding protein gene. Nature Genetics 10 383-393. (doi:10.1038/ng0895-383)

Reynard LN, Turner JM, Cocquet J, Mahadevaiah SK, Touré A, Hoog C \& Burgoyne PS 2007 Expression analysis of the mouse multi-copy X-linked gene XIr-related, meiosis-regulated $(X \mathrm{mr})$, reveals that $X \mathrm{mr}$ encodes a spermatid-expressed cytoplasmic protein, SLX/XMR. Biology of Reproduction 77 329-335. (doi:10.1095/biolreprod.107.061101)

Reynard LN, Cocquet J \& Burgoyne PS 2009 The multi-copy mouse gene Sycp3-like Y-linked (Sly) encodes an abundant spermatid protein that interacts with a histone acetyltransferase and an acrosomal protein. Biology of Reproduction 81 250-257. (doi:10.1095/biolreprod.108.075382)

Rogner UC, Wilke K, Steck E, Korn B \& Poustka A 1995 The melanoma antigen gene (MAGE) family is clustered in the chromosomal band Xq28. Genomics 29 725-731. (doi:10.1006/geno.1995.9945)

Sang L, Yang WC, Han L, Liang AX, Hua GH, Xiong JJ, Huo LJ \& Yang LG 2011 An immunological method to screen sex-specific proteins of bovine sperm. Journal of Dairy Science 94 2060-2070. (doi:10.3168/jds.2010-3350)

Seidel GE Jr 2003 Sexing mammalian sperm - intertwining of commerce, technology, and biology. Animal Reproduction Science 79 145-156. (doi:10.1016/S0378-4320(03)00162-3)

Sills ES, Kirman I, Colombero LT, Hariprashad J, Rosenwaks Z \& Palermo GD $1998 \mathrm{H}-\mathrm{Y}$ antigen expression patterns in human X- and Y-chromosome-bearing spermatozoa. American Journal of Reproductive Immunology 40 43-47. (doi:10.1111/j.1600-0897.1998.tb00387.x)

Sinclair AH, Berta P, Palmer MS, Hawkins JR, Griffiths BL, Smith MJ, Foster JW, Frischauf AM, Lovell-Badge R \& Goodfellow PN 1990 A gene from the human sex-determining region encodes a protein with homology to a conserved DNA-binding motif. Nature 346 240-244. (doi:10.1038/346240a0)

Smith K \& Spadafora C 2005 Sperm-mediated gene transfer: applications and implications. Bioessays 27 551-562. (doi:10.1002/bies.20211)

Soares S \& Barbosa J 2008 Application of recombinant antibody library for screening specific antigens in a bovine sperm cell subpopulation. Livestock Science 114 188-193. (doi:10.1016/j.livsci.2007.04.024)

Song R, Ro S, Michaels JD, Park C, McCarrey JR \& Yan W 2009 Many $X$-linked microRNAs escape meiotic sex chromosome inactivation. Nature Genetics 41 488-493. (doi:10.1038/ng.338)

Taketo MM, Araki Y, Matsunaga A, Yokoi A, Tsuchida J, Nishina Y, Nozaki M, Tanaka H, Koga M, Uchida K et al. 1997 Mapping of eight testis-specific genes to mouse chromosomes. Genomics 46 138-142. (doi:10.1006/geno.1997.5014)

Tao Y, Masly JP, Araripe L, Ke Y \& Hartl DL 2007 A sex-ratio meiotic drive system in Drosophila simulans. I: an autosomal suppressor. PLoS Biology 5 e292. (doi:10.1371/journal.pbio.0050292)

Touré A, Grigoriev V, Mahadevaiah SK, Rattigan A, Ojarikre OA \& Burgoyne PS 2004 A protein encoded by a member of the multicopy Ssty gene family located on the long arm of the mouse $Y$ chromosome is expressed during sperm development. Genomics 83 140-147. (doi:10. 1016/S0888-7543(03)00216-7)
Touré A, Clemente EJ, Ellis P, Mahadevaiah SK, Ojarikre OA, Ball PA, Reynard L, Loveland KL, Burgoyne PS \& Affara NA 2005 Identification of novel $Y$ chromosome encoded transcripts by testis transcriptome analysis of mice with deletions of the $\mathrm{Y}$ chromosome long arm. Genome Biology 6 R102. (doi:10.1186/gb-2005-6-12-r102)

Tse JY, Wong EY, Cheung AN, O WS, Tam PC \& Yeung WS 2003 Specific expression of $\mathrm{VCY} 2$ in human male germ cells and its involvement in the pathogenesis of male infertility. Biology of Reproduction 69 746-751. (doi:10.1095/biolreprod.103.015792)

Turner JM, Mahadevaiah SK, Fernandez-Capetillo O, Nussenzweig A, Xu X, Deng CX \& Burgoyne PS 2005 Silencing of unsynapsed meiotic chromosomes in the mouse. Nature Genetics 37 41-47. (doi:10.1038/ng1484)

Turner JM, Mahadevaiah SK, Ellis PJ, Mitchell MJ \& Burgoyne PS 2006 Pachytene asynapsis drives meiotic sex chromosome inactivation and leads to substantial postmeiotic repression in spermatids. Developmental Cell 10 521-529. (doi:10.1016/j.devcel.2006.02.009)

Uchida K, Tsuchida J, Tanaka H, Koga M, Nishina Y, Nozaki M, Yoshinaga K, Toshimori K, Matsumiya K, Okuyama A et al. 2000 Cloning and characterization of a complementary deoxyribonucleic acid encoding haploid-specific alanine-rich acidic protein located on chromosome-X. Biology of Reproduction 63 993-999. (doi:10.1095/ biolreprod63.4.993)

Véron N, Bauer H, Weisse AY, Lüder G, Werber M \& Herrmann BG 2009 Retention of gene products in syncytial spermatids promotes nonMendelian inheritance as revealed by the $t$ complex responder. Genes and Development 23 2705-2710. (doi:10.1101/gad.553009)

Wang PJ, McCarrey JR, Yang F \& Page DC 2001 An abundance of X-linked genes expressed in spermatogonia. Nature Genetics 27 422-426. (doi:10.1038/86927)

Wang PJ, Page DC \& McCarrey JR 2005 Differential expression of sexlinked and autosomal germ-cell-specific genes during spermatogenesis in the mouse. Human Molecular Genetics 14 2911-2918. (doi:10.1093/ hmg/ddi322)

Wang A, Yasue H, Li L, Takashima M, de León FA \& Liu WS 2008 Molecular characterization of the bovine chromodomain Y-like genes. Animal Genetics 39 207-216. (doi:10.1111/j.1365-2052.2008.01706.x)

Ward MA \& Burgoyne PS 2006 The effects of deletions of the mouse $Y$ chromosome long arm on sperm function - intracytoplasmic sperm injection (ICSI)-based analysis. Biology of Reproduction 74 652-658. (doi:10.1095/biolreprod.105.048090)

Westbrook VA, Diekman AB, Klotz KL, Khole VV, von Kap-Herr C, Golden WL, Eddy RL, Shows TB, Stoler MH, Lee CY et al. 2000 Spermatid-specific expression of the novel X-linked gene product SPAN$X$ localized to the nucleus of human spermatozoa. Biology of Reproduction 63 469-481.

Wilkerson DC \& Sarge KD 2009 RNA polymerase II interacts with the Hspa1b promoter in mouse epididymal spermatozoa. Reproduction 137 923-929. (doi:10.1530/REP-09-0015)

Yang QS, Xia F, Gu SH, Yuan HL, Chen JZ, Yang QS, Ying K, Xie Y \& Mao YM 2002 Cloning and expression pattern of a spermatogenesisrelated gene, BEX1, mapped to chromosome Xq22. Biochemical Genetics 40 1-12. (doi:10.1023/A:1014565320998)

Yang Y, Chang TC, Yasue H, Bharti AK, Retzel EF \& Liu WS 2011 ZNF280BY and ZNF280AY: autosome derived Y-chromosome gene families in Bovidae. BMC Genomics 12 13. (doi:10.1186/1471-2164-12-13)

Yao CJ, Xu WJ, Gong XL, Zhou Y, Yan ZQ, Zhu ZJ, Wang ZX, Li QL, Guo XB, Wang LY et al. 2010 The role of Dby mRNA in early development of male mouse zygotes. Asian Journal of Andrology 12 567-577. (doi:10.1038/ aja.2010.28)

Yeh YC, Yang VC, Huang SC \& Lo NW 2005 Stage-dependent expression of extra-embryonic tissue-spermatogenesis-homeobox gene 1 (ESX1) protein, a candidate marker for $X$ chromosome-bearing sperm. Reproduction, Fertility, and Development 17 447-455. (doi:10.1071/RD04077)

Zheng Y, Deng X, Zhao Y, Zhang H \& Martin-Deleon PA 2001 Spam1 ( $\mathrm{PH}-20)$ mutations and sperm dysfunction in mice with the $\mathrm{Rb}(6.16)$ or $\mathrm{Rb}$ (6.15) translocation. Mammalian Genome 12 822-829. (doi:10.1007/ s00335-001-1008-3)

Received 27 June 2011

First decision 15 August 2011

Accepted 12 September 2011 